\title{
Spatio-temporal variability of NDVI and land surface temperature in the Maule and Biobío Regions (2000-2012)
}

\author{
Luis Soto-Mardones ${ }^{1}$, and Isaac Maldonado-Ibarra ${ }^{2 *}$
}

The Intergovernmental Panel on Climate Change (IPCC, Geneva, Switzerland) reports that climatic zoning requires new methodologies to discriminate homogeneous areas due to new scenarios generating global climatic change. The objective of this study was to perform climatic zoning by analyzing spatial and temporal variability of land surface temperature (LST) and the normalized difference vegetation index (NDVI). The 20-yr sequence of MODIS (LST and NDVI) images was analyzed by harmonic analysis, empirical orthogonal functions (EOFs), and continuous wavelet cross-correlation functions. Annual harmonic analysis identified agroclimatic zones from amplitude and phase, this result was valid for the two first EOF modes that account for $74 \%$ of the annual signal. Wavelet cross-correlations between the NDVI and LST temporal series showed a wideband high-power spectrum associated with the annual cycle. Finally, the methodologies applied to LST and NDVI images allowed the identification of agroclimatic zones. The study area included different dryland zones (coastal, interior, and foothill), irrigated valleys, and forests.

Key words: Agroclimatic zones, coastal/interior/foothill drylands, vigor index.

\section{INTRODUCTION}

The impact of climatic change makes it necessary to better characterize the productive conditions of agroecological zones where agriculture is carried out. Information provided by the National Oceanic and Atmospheric Administration Advanced (NOAA, Washington, DC, USA) satellite series is currently of great interest for vegetation and temperature monitoring on a regional scale because this tool is useful for planning and sustainable management of natural resources. Similarly, the availability of moderate resolution imaging spectroradiometer (MODIS) sensor images provided by the Terra satellite have enhanced the quality of this type of studies due to its higher image resolution as compared with advanced very high resolution radiometer (AVHRR) images (Karlsen et al., 2008). Flores and Lillo (2010) report some MODIS image applications complemented by the topographic platform of the Shuttle Radar Topography Mission, and they estimate spatial variation of air temperature solely from remotely sensed data in different geomorphological zones.

${ }^{1}$ Universidad del Bío-Bío, Facultad de Ciencias, Av. Collao 1202, Casilla 5-C, Concepción, Chile.

${ }^{2}$ Instituto de Investigaciones Agropecuarias, INIA Quilamapu, Av. Vicente Méndez 515, Chillán, Chile.

*Corresponding author (imaldona@inia.cl).

Received: 13 November 2014.

Accepted: 8 July 2015.

doi:10.4067/S0718-58392015000500008
Four agroclimatic zones were defined in the study area with longitudinal locations: coastal dryland, interior dryland, irrigated central valley, and Andean foothills (ODEPA, 2000). These studies used random data from meteorological stations, which were used to generate the agroclimatic map of Chile (Novoa et al., 1989) and agroecological zoning of the Maule and Biobío Regions (Del Pozo and Del Canto, 1999).

The climate of the study area has been described in different bioclimatic or agroclimatic studies in Chile (Rivera et al., 2007), leading to different classifications. In general, the area has a Mediterranean climate with cold and wet periods in winter and hot and dry periods in summer. It also has a large interannual variation in precipitation. The orography of the analyzed area is very irregular because it is delimited by the Pacific Ocean to the west and the Andes Range to the east. The Coastal Range is found at the limit of the coastline, and the intermediate valley is located between both mountain ranges.

The land surface temperatures (LSTs) have been used to calculate the energy flows between the atmosphere and the soil to improve the global weather forecast model and agricultural applications, quantify drought by estimating surface soil moisture, and identify homogeneous zones (Mattar et al., 2008). On the other hand, spatio-temporal variability of the NDVI images have led to monitoring phenological processes (Kramer et al., 2000; Primack et al., 2004), forest management (Hartkamp et al., 2002; Maselli, 2004; Beck et al., 2006), interactions between climate and forest ecosystems (Piao et al., 2003; Luo and Piwowar, 2006; Guo et al., 2007), relationships between 
the moisture index and annual rainfall cycles, and global warming studies (Laurance and Williamson, 2001; Yao et al., 2011).

The level of spatial and temporal detail that is provided by LST and NDVI satellite images allow more precise climatic zoning with respect to images based on specific and random data from meteorological stations (Parra et al., 2006). Therefore, the objective of this study was to perform climatic zoning in homogeneous areas based on the spatial and temporal variability of LST and NDVI by evaluating goodness-of-fit using specific mathematical functions.

\section{MATERIALS AND METHODS}

The study area included the Maule and Biobío Regions in central Chile, which are located between the Coastal Range and the Andes Range and typified by their important agricultural activity. The variables selected for this study were NDVI and LST. The NDVI is used primarily in remote sensing to identify vegetation vigor status. This indicator has been used in numerous vegetation studies (Karlsen et al., 2008; Chen et al., 2011).

Characterization was performed with LST and NDVI values; both data sets corresponded to the MOD11A2 and MOD13A2 products generated from the images supplied by the MODIS sensor on board the TERRA satellite (MODIS, 2012). The LST product is the simple 8-d average pointing out the contaminated pixels through image quality assurance (QA) (Wan, 2006). Only images corresponding to daytime temperature were used in this study. Image precision has been validated in more than 20 in situ measurements under clear sky conditions with a 1 Kelvin (K) precision ranging from 263 to $322 \mathrm{~K}$ (Wan, et al., 2002; 2004). However, the MODIS sensor is not problem-free; one drawback is the uncertainty of the continuous temperature variation and the influence of these atmospheric conditions in both the original bands and level 3 products (Huang et al., 2008). On the other hand, NDVI image characteristics have similar temperature problems although the method used to generate images is different; maximum value compositing (MVC) results in an NDVI product every $16 \mathrm{~d}$. This method is described by Holben (1986) and product characteristics and their disadvantages are found in Huete et al. (2002). Spatial resolution of both products is close to $1 \mathrm{~km}$ and each of these images was georeferenced in the sinusoidal projection using values that accompanied each product.

The Maule and Biobío Regions were determined from the NDVI and LST global images; they are located between the $34^{\circ} 41^{\prime}$ and $38^{\circ} 30^{\prime} \mathrm{S}$ parallels and have areas of 30269 and $37068 \mathrm{~km}^{2}$, respectively. Images were averaged monthly and a preliminary analysis identified atypical data of both variables. The NDVI data were considered as valid in the present study when they were between 0.1 and 1 (Table 1), whereas the valid range fluctuated between -20 and $50{ }^{\circ} \mathrm{C}$ for LST.
Table 1. Normalized difference vegetation index (NDVI) ranges defined for this study.

\begin{tabular}{lc}
\hline NDVI Ranges & Classification \\
\hline $0.8<$ NDVI $<1.0$ & Very high \\
$0.6<$ NDVI $<0.8$ & High \\
$0.4<$ NDVI $<0.6$ & Medium \\
NDVI $<0.4$ & Low \\
\hline
\end{tabular}

Fourier analysis was applied to the NDVI and LST images in the present study to explore the temporal variation of both variables in the frequency domain (not shown). The annual signal dominated and significant low frequency harmonics also appeared. Exact frequencies of these signals were fitted by least squares and the following equation:

$$
\psi(x, y, t)=\operatorname{Re}\left\{\phi(x, y) e^{-i[\omega t-\theta(x, y)]}\right\}
$$

where $\psi$ represents NDVI or LST and $\phi$ and $\theta$ are amplitude and phase, respectively, of each harmonic frequency $\omega$.

Spatial structure and temporal variability were also calculated by the empirical orthogonal functions (EOFs), which are applied based only on statistical considerations. The EOFs allow the quantification of total variance of the series (NDVI and LST) in modes that are orthogonal or independent to one another. This is how modes or structures having the highest percentage of variance are obtained, which probably represent the signals of the dominant variables in the region under study, and the contributions associated with another type of process or scale remain in the lower modes. The EOF analyses were applied to the monthly series to study the behavior of the annual signal (12-mo period). The annual signal was then obtained from the series (NDVI and LST) with a low pass filter to obtain the interannual anomalies to compare them to the El Niño index reported by the NOAA Climate Prediction Center.

To characterize specific zones found in both regions under study, 10 points were identified that represent the coastal dryland, interior dryland, irrigated valley, Andean foothills, and forest areas (Table 2). Temporal series were calculated at each point, which were normalized, the trend eliminated, and wavelet cross-correlations applied. This tool also allowed the comparison and cross-correlation between two time series (Maraun and Kurths, 2004; Maraun et al., 2007; Schaefli and Gupta, 2007).

Table 2. Point coordinates associated with forestry and agricultural zones of the study.

\begin{tabular}{|c|c|c|c|c|}
\hline Region & $\begin{array}{l}\text { Agroecological } \\
\text { zone }\end{array}$ & Location & Latitude & Longitude \\
\hline \multirow[t]{5}{*}{ Maule } & Coastal Dryland & Chanco & $35^{\circ} 42^{\prime} 50^{\prime \prime} \mathrm{S}$ & $72^{\circ} 31^{\prime} 26^{\prime \prime} \mathrm{W}$ \\
\hline & Interior Dryland & San Rafael & $35^{\circ} 7^{\prime} 15^{\prime \prime} \mathrm{S}$ & $71^{\circ} 48^{\prime} 58^{\prime \prime} \mathrm{W}$ \\
\hline & Foothill Dryland & Quinamávida & $35^{\circ} 47^{\prime} 34^{\prime \prime} \mathrm{S}$ & $71^{\circ} 26^{\prime} 25^{\prime \prime} \mathrm{W}$ \\
\hline & Irrigated Valley & San Clemente & $35^{\circ} 29^{\prime} 14^{\prime \prime} \mathrm{S}$ & $71^{\circ} 30^{\prime} 12^{\prime \prime} \mathrm{W}$ \\
\hline & Forest Area & Constitución & $35^{\circ} 19^{\prime} 54^{\prime \prime} \mathrm{S}$ & $72^{\circ} 21^{\prime} 47^{\prime \prime} \mathrm{W}$ \\
\hline \multirow[t]{5}{*}{ Biobío } & Coastal Dryland & Cañete & $37^{\circ} 54^{\prime} 22^{\prime \prime} \mathrm{S}$ & $73^{\circ} 25^{\prime} 40^{\prime \prime} \mathrm{W}$ \\
\hline & Interior Dryland & Ninhue & $36^{\circ} 25^{\prime} 09^{\prime \prime} \mathrm{S}$ & $72^{\circ} 19^{\prime} 51^{\prime \prime} \mathrm{W}$ \\
\hline & Foothill Dryland & Tucapel & $37^{\circ} 17^{\prime} 34^{\prime \prime} \mathrm{S}$ & $71^{\circ} 52^{\prime} 60^{\prime \prime} \mathrm{W}$ \\
\hline & Irrigated Valley & Los Ángeles & $37^{\circ} 28^{\prime} 8^{\prime \prime} \mathrm{S}$ & $72^{\circ} 15^{\prime} 41^{\prime \prime} \mathrm{W}$ \\
\hline & Forest Area & Laraquete & $37^{\circ} 11^{\prime} 56^{\prime \prime} \mathrm{S}$ & $73^{\circ} 7^{\prime} 12^{\prime \prime} \mathrm{W}$ \\
\hline
\end{tabular}


The purpose of this analysis was to evaluate: the relationship between pairs of series (LST and NDVI) for time and frequency, the domination of one series or variable over another, that is, display the period of time and frequency in which the relationship is significant in terms of power spectrum, identify if the series or variables are in phase or phase shift (increase or decrease together, or have inverse behaviors), and the possible domination or influence of one over the other.

\section{RESULTS}

\section{Harmonic analysis of NDVI monthly images}

This analysis of the annual component of the Maule and Biobío Regions allowed us to obtain the spatial distributions of amplitude (Figure 1a) and phase (Figure 1b).

An area with minimum variability was observed in the amplitude close to 0.02 , which is illustrated in dark blue, and covers most of the coastline, coastal dryland, and Nahuelbuta and Coastal Ranges. According to the agroclimatic distribution by Del Pozo and Del Canto (1999), this classification coincides with the following zones: Empedrado, Nahuelbuta Range, and parts of Concepción and Hualañé (Figure 1a). This area is mainly associated with sectors of evergreen forests (radiata pine and Eucalyptus spp.) that reach a phase with maximum amplitudes in the first 2-mo of the year (2- to 3-mo) associated with the Southern Hemisphere summer (Figure 1b).

The distribution that was observed for amplitudes close to 0.05 covers most of the study area as illustrated by the

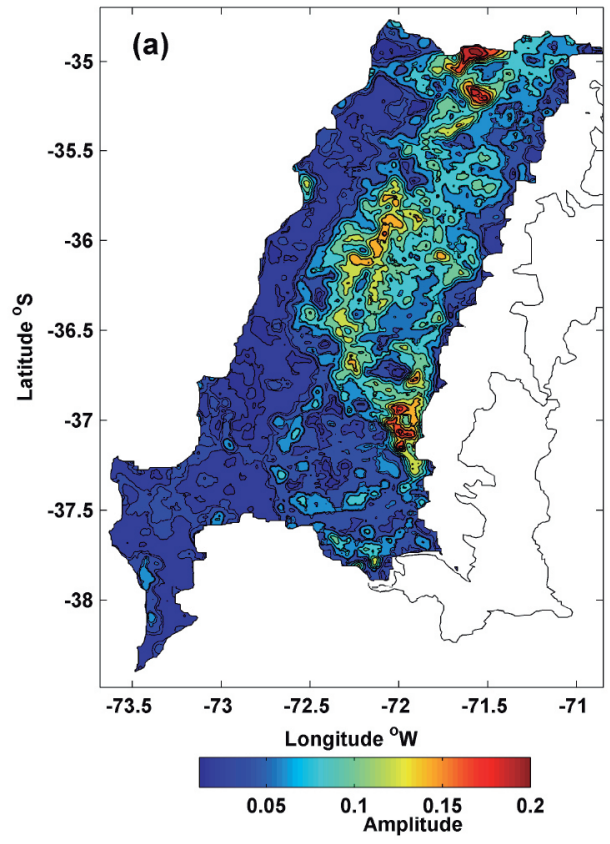

light blue background (Figure 1a). The strip of coastal dryland includes the agricultural areas of ConstituciónChanco and Arauco-Cañete, where maximum amplitudes occurred in June and September (Figure 1b), respectively. On the other hand, the intermediate plain $\left(36^{\circ} 47^{\prime}\right.$ to $38^{\circ} 23^{\prime}$ $S$ lat) in the south of the Biobío Region was characterized by forest sectors associated with a 3-mo phase (Figure 1b) and was mixed with agricultural sectors with phases fluctuating between 5- and 9-mo (Figure 1b). Agriculture in this area consists mainly of irrigated crops, such as sugar beet, chicory, maize, high producing grasslands, and fruit trees.

Figure 1a shows the intermediate plain $\left(34^{\circ} 42^{\prime}\right.$ to $36^{\circ} 47^{\prime} \mathrm{S}$ lat) with the highest amplitudes (0.1 to 0.2$)$ which are explained by grasslands and dryland farming with a phase oscillating between 5 and 8-mo (Figure 1b). In the northernmost part of the study area, there were two locations with higher annual amplitude variability (close to 0.2 ) associated with aridity.

Finally, an area with higher amplitude variability (Figure 1a) was observed in the foothills (36 $39^{\prime}$ to $37^{\circ} 19^{\prime}$ $S$ lat) with maximum amplitude occurring in September and October. High amplitude and phase variability is explained by the fact that this zone is characterized by cereal cultivation.

The LST annual harmonic (Figures $2 \mathrm{a}$ and $2 \mathrm{~b}$ ) had low amplitudes ranging between 3 and $5{ }^{\circ} \mathrm{C}$ found in the coastal dryland (Figure 2a) associated with the Pacific Ocean temperature control. The latitudinal strip with $6{ }^{\circ} \mathrm{C}$ amplitudes covered the eastern edge of the Coastal Range and part of the intermediate depression and was displaced to the foothills in the southern sector of the study area. Figure 2 a shows maximum amplitudes $\left(8\right.$ to $\left.9{ }^{\circ} \mathrm{C}\right)$ found

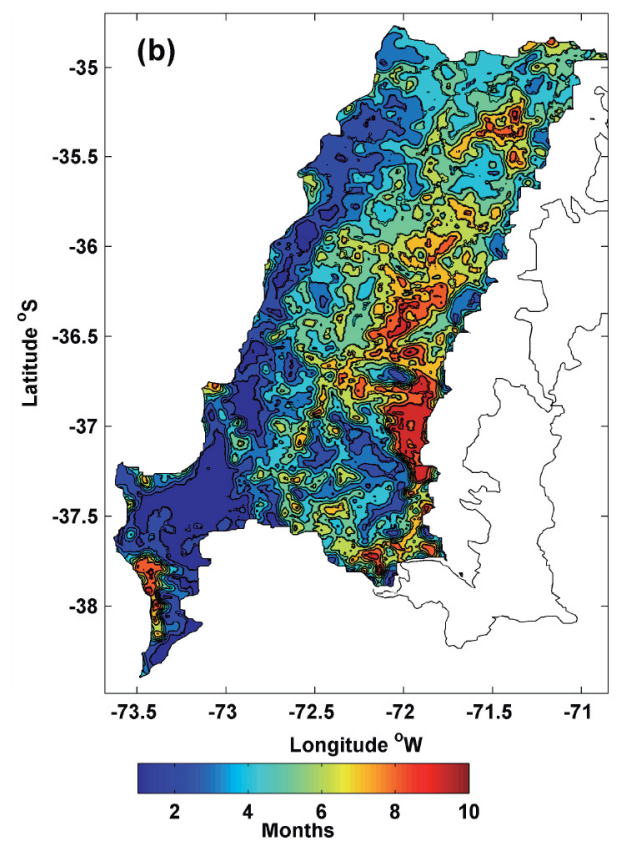

Figure 1. Spatial distribution of (a) amplitude and (b) phase (months) for the annual component of the normalized difference vegetation index (NDVI) for the Maule and Biobío Regions. 

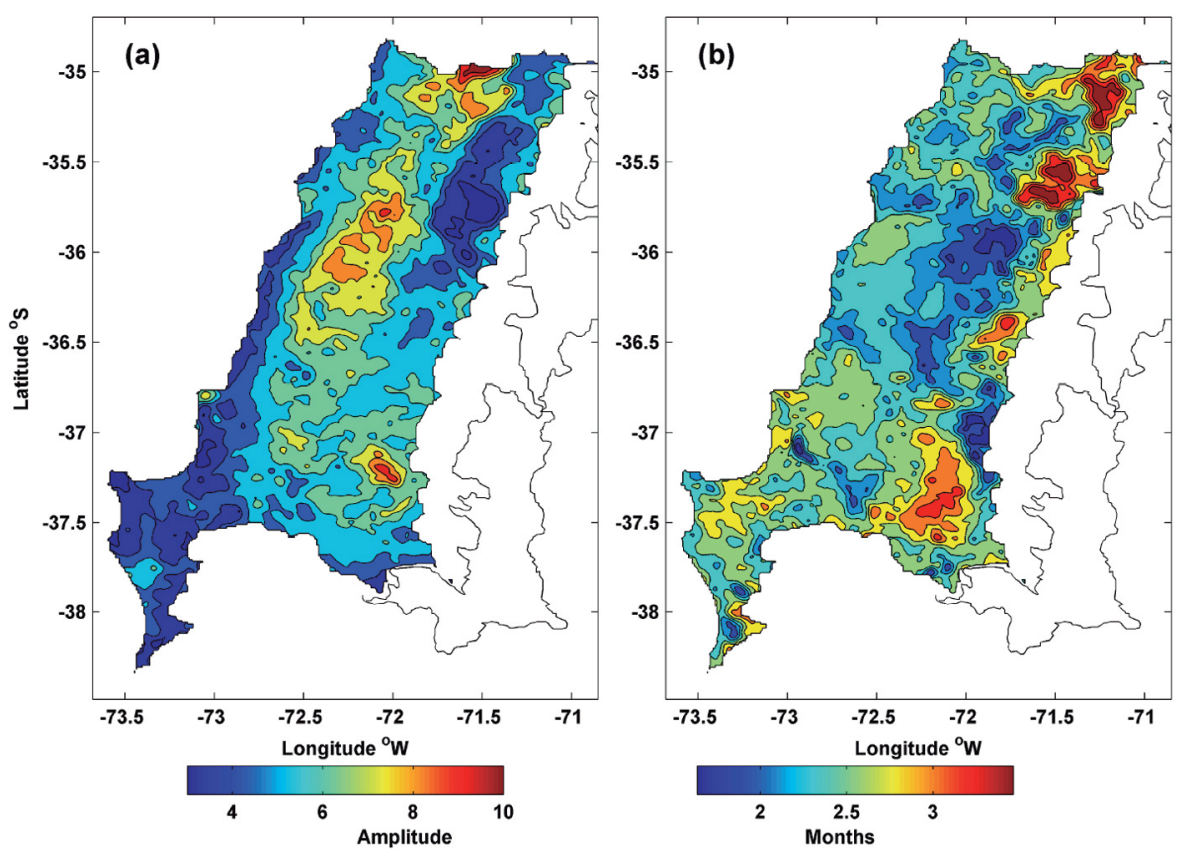

Figure 2. Spatial distribution of (a) amplitude and (b) phase (months) for the annual component of the land surface temperature (LST) index for the Maule and Biobío Regions.

in the central part of the intermediate depression and a location in the southern area of the Andean foothills. Maximum amplitudes occurred in February and March in the study area (Figure 2b). These fluctuations in the phase are explained by the type of plant cover, soil type, and topography.
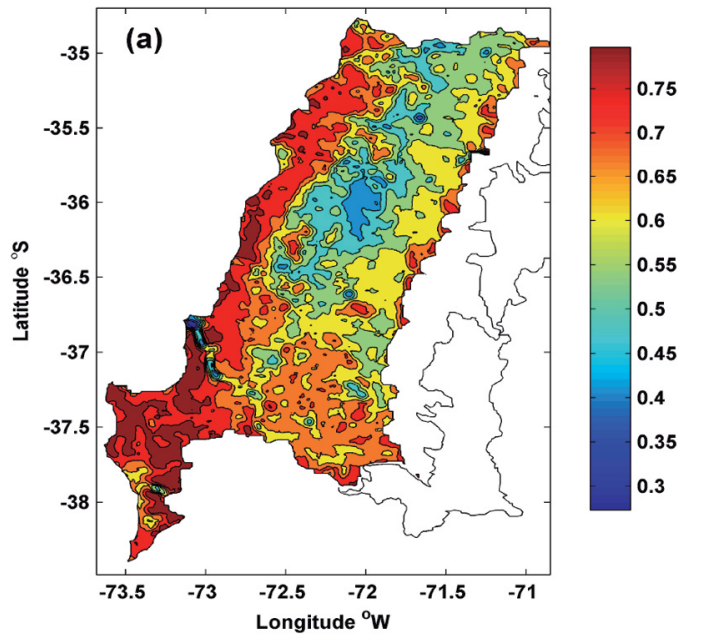

\section{Empirical orthogonal functions}

The empirical orthogonal functions (EOFs) were applied to the monthly NDVI image sequence (Figure 3) and a dominant signal was observed; this is represented by mode 1 corresponding to the seasonal variation (blue) in Figure $3 \mathrm{c}$; it accounts for most of the variance, that is,
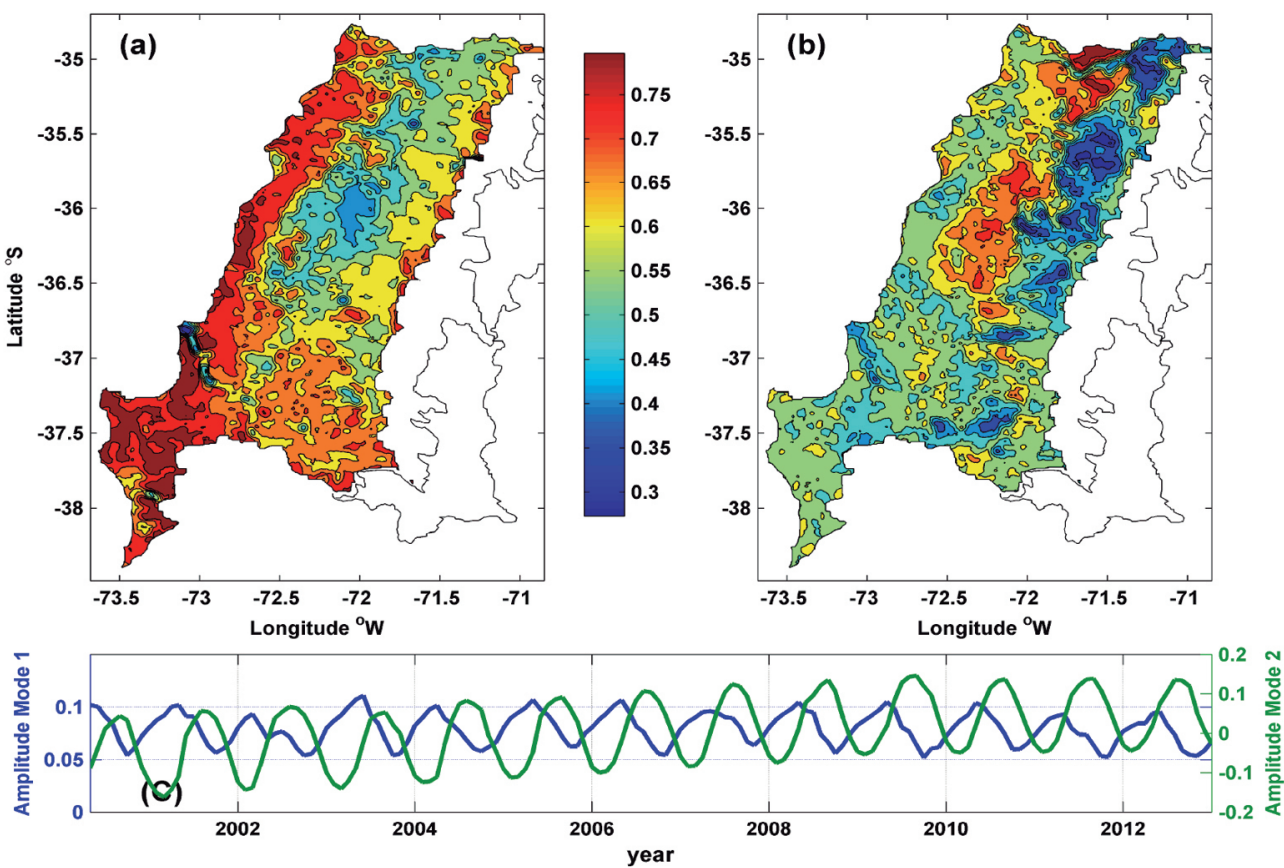

Figure 3. Empirical orthogonal functions of monthly normalized difference vegetation index (NDVI) for the Maule and Biobío Regions: (a) and (b) spatial structures of the two modes and (c) temporal variability of modes 1 and 2. 
$67 \%$ of variability. The first spatial mode (Figure 3a) was a longitudinal band with a very high vigor index (Table 1) that included both the Coastal Range and dryland associated with forest sectors (plantations and native forest). There was an area with a medium vigor index in the northern part of the intermediate depression $\left(34^{\circ} 30^{\prime}\right.$ to $36^{\circ} 30^{\prime} \mathrm{S}$ lat) which included the interior dryland and irrigated valley. This area is characterized by significant agricultural activity under irrigated and dryland conditions. A high vigor index was observed in the southern part of the intermediate depression $\left(36^{\circ} 30^{\prime}\right.$ to $37^{\circ} 48^{\prime} \mathrm{S}$ lat) and the Andean foothills, which is associated with large areas of forest and irrigation agriculture.

Mode 2 (Figure 3b) contributed $7 \%$ of the total variance; temporal variability was also annual although it was in opposite phase to mode 1 . The spatial structure of the mode 2 (Figure $3 \mathrm{~b}$ ) in the northern part of the intermediate depression $\left(34^{\circ} 30^{\prime}\right.$ to $36^{\circ} 50^{\prime}$ 'S lat) exhibited a medium vigor index, while it was low in the rest of the area.

Temporal variability of the mode 1 reached its maximum amplitude in March and April, while it occurred between June and July for mode 2 (Figure 3c) with a 2to 3-mo phase shift. A decrease in amplitude over time was also observed in the temporal evolution of the two modes, and it is possible to associate this trend with global warming.

Mode 1 explains $40 \%$ of total variance when applying EOFs to the monthly LST image sequence. The spatial structure of LST mode 1 (Figure 4a) showed the highest amplitudes on the intermediate plain and these declined towards the Biobío Region; this result is consistent with the topographic profile of the study area. Agricultural areas with higher LST were the interior dryland and part of the irrigated valley. The coastal dryland and part of the coastal range exhibited lower amplitudes mainly because of ventilation provided by the Pacific Ocean and greater vegetation in that area. Temporal evolution of mode 1 (Figure 4c) exhibited seasonal behavior with maximum amplitude occurring in February, which is clearly associated with the Southern Hemisphere summer.

On the other hand, mode 2 accounts for $8 \%$ of total variance where spatial structure (Figure 4b) had maximum amplitudes on the edge of the Andes Range (Maule Region) and minimum amplitudes in the rest of the study area. Temporal variability of mode 2 exhibited seasonal behavior (Figure 4c) and was in opposite phase to mode 1 (Figure 4c). Furthermore, LST temporal evolutions (Figure 4c) of both modes revealed a decrease in amplitudes over time; this behavior was similar to the first two NDVI modes (Figure 3c).

\section{Correlations by means of continuous wavelet transforms}

Continuous wavelet transforms (CWT) were applied to the LST and NDVI time series; these were compared to areas with similar agroclimatic conditions in the north (Maule) and south (Biobío).

Chanco (Maule) and Cañete (Biobío) coastal dryland area. Spectral maps (Figures 5a and 5c) showed a marked band with high power spectrum clearly associated with
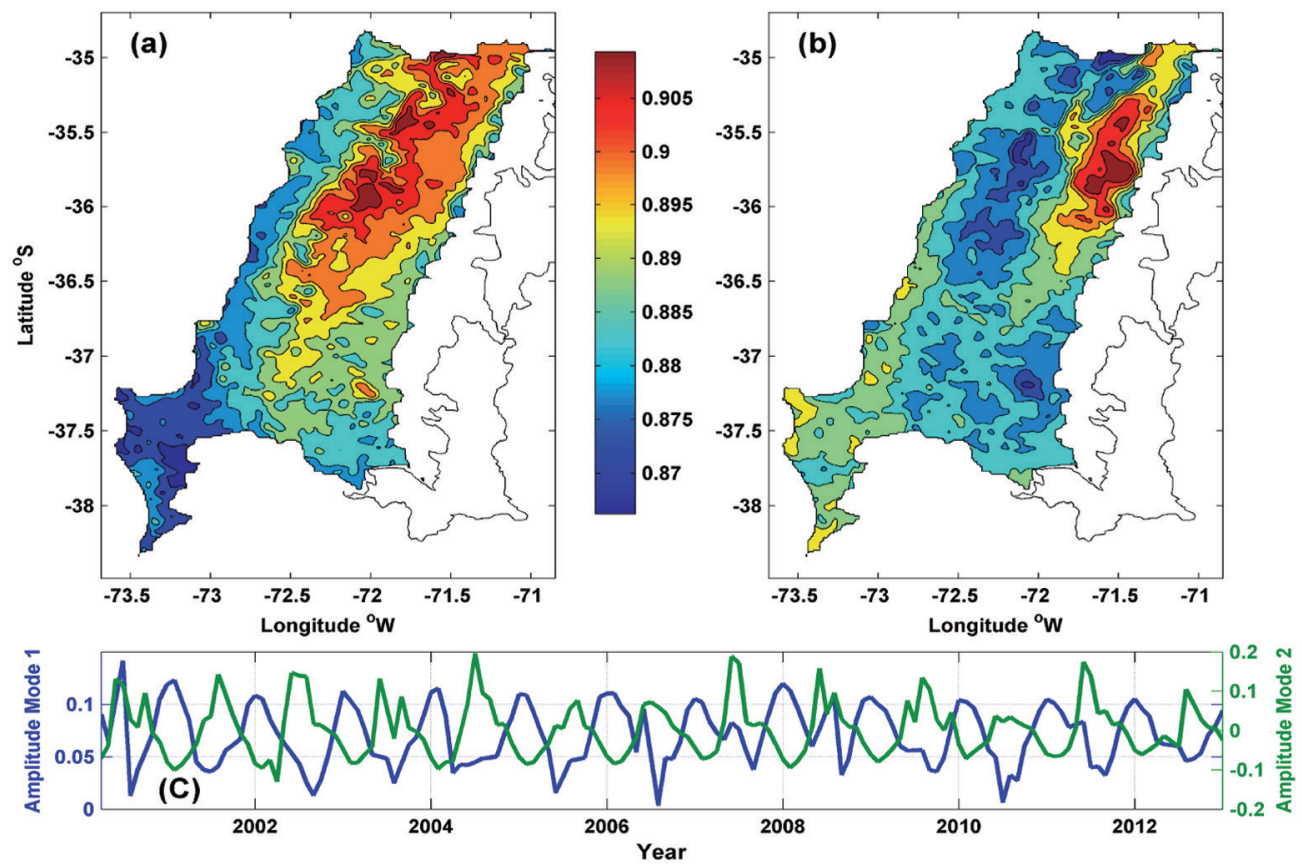

Figure 4. Empirical orthogonal functions of monthly land surface temperature (LST) for the Maule and Biobío Regions: (a) and (b) spatial structures of the two modes and (c) temporal variability of modes 1 and 2 . 

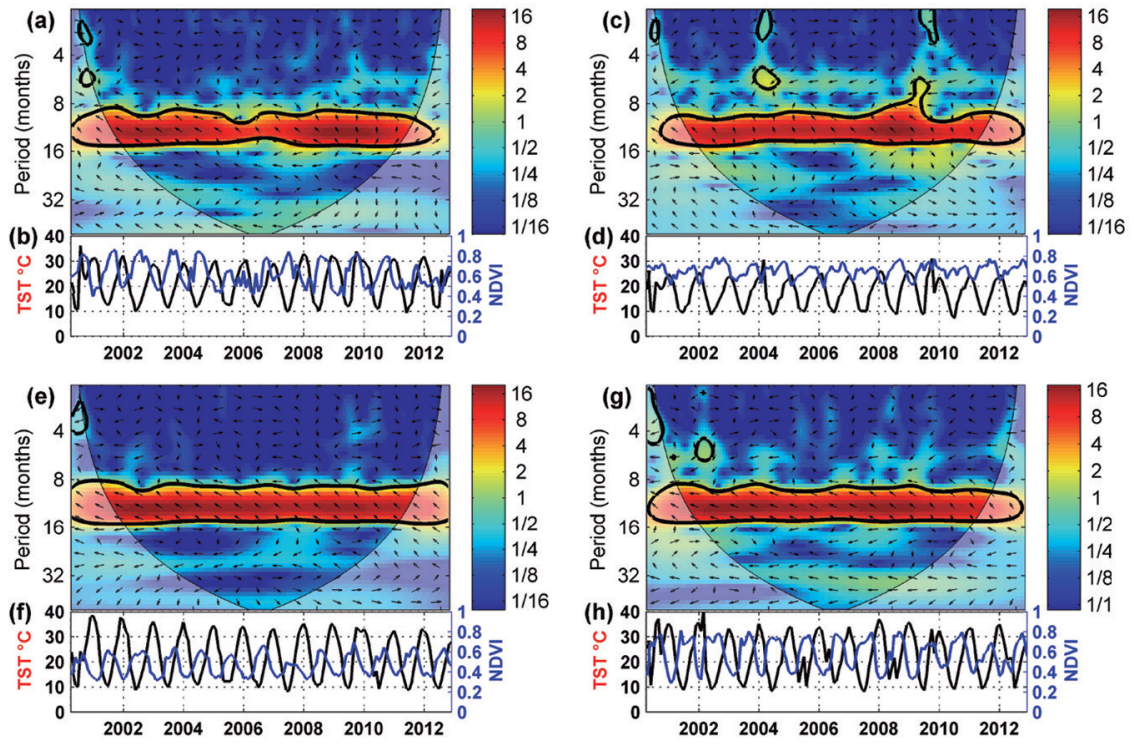

Figure 5. Wavelet cross-correlations between land surface temperature (TST) and normalized difference vegetation index (NDVI) for different forestry and agricultural zones: coastal dryland of Chanco-Maule (a and b) and Cañete-Biobío (c and d); interior dryland of San Rafael-Maule (e and f) and Ninhue-Biobío (g and h).

the annual cycle between the two variables. This band was approximately a 12-mo period or 1 year on the frequency scale and crossed the time domain. The LST and NDVI series were found in opposite phase form 2000 to 2009, which was associated with dryland conditions; this process was interrupted at the end of 2009 when the series shifted $90^{\circ}$ because of early rainfall in the summer months. The annual spectral band of the Maule coastal dryland (Figure 5a) displayed thinning throughout the frequency domain (around 2006) due to a decrease in the NDVI value (Figure $5 \mathrm{~b}$ ) in this period. In contrast, the annual spectral band of the Biobío coastal dryland (Figure 5c) showed disturbance at the end of 2009 caused by an increase in LST (Figure 5d).

The NDVI temporal series (Figures $5 b$ and $5 d$ ) were part of the high vigor index; however, the seasonal amplitudes of the Maule dryland exhibited higher variability than the Biobío dryland. The LST temporal series of the Maule dryland (Figure 5b) showed that maximum LSTs were higher than those of the Biobío dryland (Figure 5d); Figures $2 \mathrm{a}$ and $4 \mathrm{a}$ confirm these data.

San Rafael (Maule) and Ninhue (Biobío) interior dryland area. The spectral maps (Figures $5 \mathrm{e}$ and $5 \mathrm{~g}$ ) illustrated a wideband high-power spectrum associated with the annual cycle between the two variables. These were in opposite phase because the phase angle had a negative direction. The annual spectral bands of the interior dryland of both regions (Figures $5 \mathrm{e}$ and $5 \mathrm{~g}$ ) are not altered through the time domain.

The Maule (Figure 5f) and Biobío (Figure 5h) NDVI temporal series had significantly different amplitudes and vigor indices were medium and high, respectively; this can be explained by the type of plant cover: San Rafael has a permanent natural grassland, whereas Ninhue has both grasslands and cereal crops, higher hawthorn density, and a higher rainfall regime. The LST (Figure 5f) reached higher temperatures in the San Rafael interior dryland because of its geographic location (Figures 2a and 4a).

Quinamávida (Maule) and Tucapel (Biobío) foothill dryland. The spectral map (Figure 6a) of Quinamávida foothill dryland showed a band with high-power spectrum associated with the annual cycle. Seasonal continuity was interrupted in the 2004-2007 period; the two variables were in phase in both segments (2000-2004 and 2007-2012) due to their positive direction. This seasonal segmentation trend was repeated in the spectral map of Tucapel foothill dryland (Figure 6c) although it was shorter (2005-2006). The two variables were in opposite phase in the first segment (2000-2005) and the phase shift was $270^{\circ}$ in the second segment (2006-2012). The spectral bands of both areas also influenced the high frequency bands.

The Maule (Figure 6f) and Biobío (Figure 6h) NDVI temporal series had medium and high vigor indices, respectively. The Maule (Figure 6f) LST amplitude also had a lower variability than Tucapel (Figure 6h) given that the maximum temperature occurred in the northern region (Figures $2 \mathrm{a}$ and $4 \mathrm{a}$ ).

San Clemente (Maule) and Los Ángeles (Biobío) irrigated valley. The spectral map (Figure 6e) of the San Clemente irrigated valley highlighted a seasonal band with high power spectrum throughout the time domain between the two variables. Two significant locations were associated with a semi-annual signal for the 2004-2008 

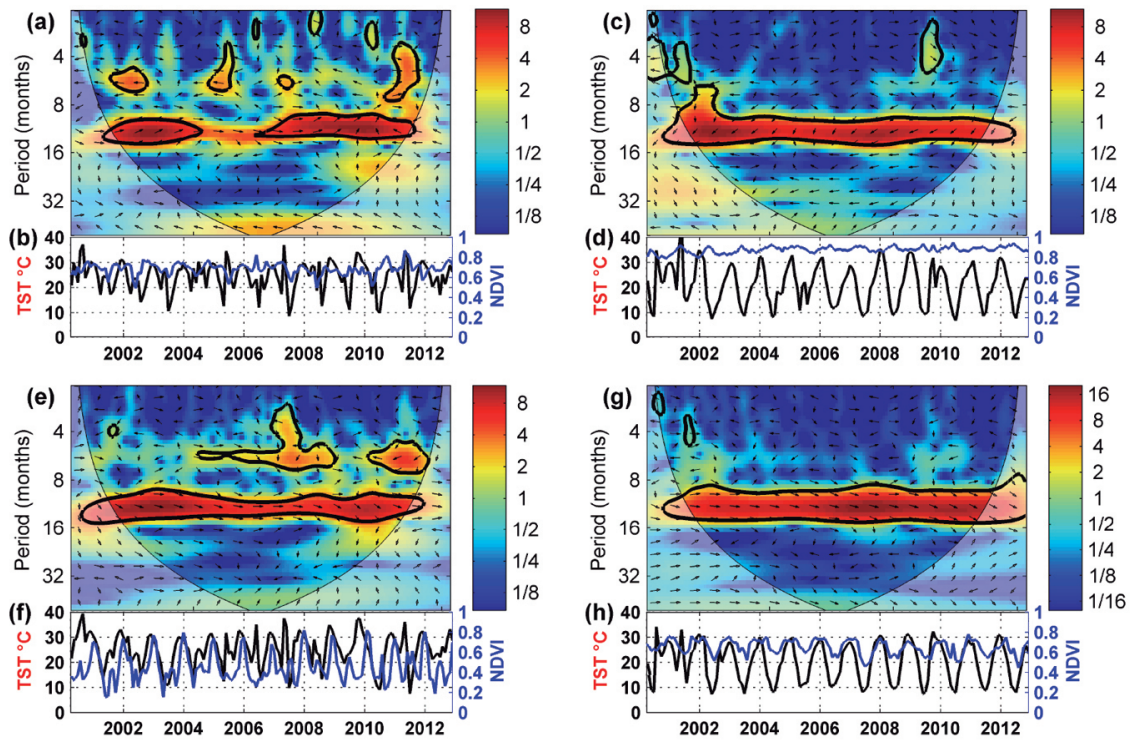

Figure 6. Wavelet cross-correlations between land surface temperature (TST) and normalized difference vegetation index (NDVI) for different forestry and agricultural zones: foothill dryland of Quinamávida-Maule (a and b) and Tucapel-Biobío (c and d); irrigated valley of San Clemente-Maule (e and f) and Los Ángeles-Biobío (g and h).

and 2010-2011 periods. This behavior was not observed on the Los Ángeles irrigated valley spectral map (Figure $6 \mathrm{~g}$ ) since it only showed a marked seasonal signal throughout the time domain. It was emphasized that both variables in these two regions were in phase due to their positive direction throughout the time domain. The NDVI temporal series of the Maule irrigated valley exhibited higher seasonal variability (Figure 6f) than the Biobío irrigated valley (Figure 6h) although both were quantified with a medium and high vigor index, respectively. On the other hand, the LST series of the Biobío Region (Figure 6f) exhibits higher seasonal variability than the Maule Region (Figure 6h).

Constitución (Maule) and Coronel (Biobío) forest area. The spectral maps related to the forest areas of the Maule (Figure 7a) and Biobío Regions (Figure 7c) showed bands with high seasonal power spectrum throughout the time domain between the two variables. They were also in opposite phase due to their negative direction. The NDVI temporal series (Figures $7 \mathrm{~b}$ and 7d) had a very high vigor index. On the other hand, similarities in amplitudes of both regions are noted in the LST series (Figures 7b and 7c).

\section{DISCUSSION}

In the temporal evolution of NDVI and LST, dominance of the annual cycle was detected with an evident difference in amplitude from west to east. Harmonic analysis proves to be a useful tool in identifying types of plant covers (Baeza, 2010) based on climatic conditions. High vigor indices during the year were associated with low amplitude variability (Figure 1a) that reached its maximum during the Southern Hemisphere summer (Figure 1b); these conditions were in accordance with the literature (Novoa y Villaseca, 1989; Del Pozo and Del Canto, 1999; ODEPA, 2000) and defined as coastal dryland. Moreover, the high vigor index was promoted by the reduction of the LST amplitudes (Figure 2a) as a result
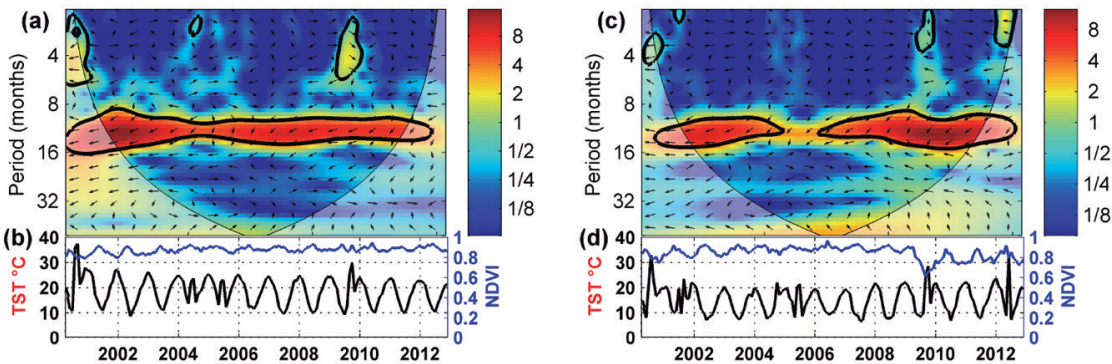

Figure 7. Wavelet cross-correlations between land surface temperature (TST) and normalized difference vegetation index (NDVI) for different forestry and agricultural zones: forest area of Constitución-Maule (a and b) and Coronel-Biobío (c and d). 
of the influence of the Pacific Ocean on the coastal plains (Flores and Lillo, 2010). In contrast, the intermediate depression area that is protected by ventilation from the Pacific Ocean by the Coastal Range generates low vigor indices as a result of high LST values and promotes grasslands and dryland farming (Flores and Lillo, 2010).

The NDVI mean varied from east to west (Figures $3 \mathrm{a}$ and $3 b$ ) and the annual scale (Figure $3 c$ ) was responsible for most of this variability. Two oscillation modes described this signal: the first (Figure 3a) in phase throughout the area with amplitudes shown in the harmonic analysis (Figure 1a) and the second (Figure 3b) with a lower amplitude and higher oscillation in the foothill region associated with higher cereal crop productivity. On the other hand, mean LST (Figures 4a and 4b) is also dominated by the annual cycle where the two modes describe the annual cycle (Figure 4c); one is influenced by the topographic conformation (Flores and Lillo, 2010), and the other has lower amplitude and higher oscillation in the region of the Andes Range.

The analysis of both variables using satellite images has allowed the characterization of typical agroclimatic zones whose boundaries differ from those proposed in the literature (Novoa y Villaseca, 1989; Del Pozo and Del Canto, 1999; ODEPA, 2000).

Finally, the study of the NDVI and LST temporal series by wavelet cross-correlations allow the characterization of three specific agroclimatic zones (drylands, irrigated valleys, and forests). The crosscorrelations of the NDVI and LST temporal series in all the regions showed a wideband high-power spectrum associated with an annual cycle. Moreover, the behavior of the coastal and intermediate fringe is different than in the foothill area because the variables (LST and NDVI) of the coastal (coastal dryland) and intermediate (interior dryland and irrigated valley) fringe are in opposite phase, whereas they are in phase towards the foothill fringe.

\section{CONCLUSIONS}

The annual scale with two oscillation modes accounting for high vigor zones was mainly responsible for mean normalized difference vegetation index (NDVI) spatial variability. Similarly, mean land surface temperature (LST) was also dominated by the annual cycle where the first two oscillation modes accounted for the influence of topography. The reduction of LST on the coastal plains is due to the influence of the Pacific Ocean, increased LST in the intermediate zone is due to the protection of the Coastal Range, and decreased LST is due to the Andes Range.

In the temporal evolution of the NDVI and LST series in the Maule and Biobío Regions, the dominant signal of the annual cycle was detected with an obvious difference in amplitude from the coast to the foothills.
The high power spectrum associated with an annual cycle was emphasized by wavelet cross-correlations between the NDVI and LST temporal series. Moreover, it was possible to define agroclimatic zones (coastal, interior, and foothill drylands, irrigated valleys, and forests) from the amplitude and phase. Continuous wavelet transforms prove to be a useful tool in identifying agroclimatic zones.

Information provided by the NDVI and LST images allowed identifying and separating areas with homogeneous behavior with respect to the climatic conditions associated with vegetation behavior.

\section{ACKNOWLEDGEMENTS}

Research was conducted thanks to contributions by the Instituto de Investigaciones Agropecuarias, INIA Quilamapu, and the Universidad del Bío-Bío.

\section{LITERATURE CITED}

Baeza, C. 2010. Variabilidad espacial y temporal de la temperatura superficial de la tierra (TST) en la zona centro sur de Chile (VIVII-VIII). 45 p. Tesis Ingeniería en Estadística Universidad del Bío-Bío, Facultad de Ciencias, Concepción, Chile.

Beck, P.S.A., C. Atzberger, K.A. Høgda, B. Johansen, and A.K. Skidmore. 2006. Improved monitoring of vegetation dynamics at very high latitudes: a new method using MODIS NDVI. Remote Sensing of Environment 100:321-334. doi:10.1016/j. rse.2005.10.021.

Chen, F.J., Y.J. Shen, Q.L. Hu, Y.Q. Qi, and Y.C. Zhang. 2011. Responses of NDVI to climate change in the Hai Basin. Journal of Remote Sensing 15:401-414.

Del Pozo, A., and P. Del Canto. 1999. Áreas agroclimáticas y sistemas productivos en la VII y VIII regiones. Serie Quilamapu $\mathrm{N}^{\mathrm{o}}$ 113. Instituto de Investigaciones Agropecuarias INIA, Chillán, Chile.

Flores, F., and M. Lillo. 2010. Simple air temperature estimation method from MODIS satellite images on a regional scale. Chilean Journal of Agricultural Research 70:436-445.

Guo, Z., Z. Wang, K. Song, B. Zhang, F. Li, and D Liu. 2007. Correlations between forest vegetation NDVI and water/thermal condition in Northeast China forest regions in 1982-2003. Chinese Journal of Ecology 26:1930-1936.

Hartkamp, A.D., G. Hoogenboom, R.A. Gilbert, T. Benson, S.A. Tarawali, A.J. Gijsman, et al. 2002. Adaptation of the CROPGRO growth model to velvet bean (Mucuna pruriens). II. Cultivar evaluation and model testing. Field Crops Research 78:27-40.

Huang, C.H., X. Li, and L. Lu. 2008. Retrieving soil temperature profile by assimilation MODIS LST products with ensemble Kalman filter. Remote Sensing of Environment 112:1320-1336.

Holben, B.N. 1986. Characteristics o maximum-value composite image from temporal AVHRR data. International Journal of Remote Sensing 7:1417-1464.

Huete, A., K. Didan, T. Miura, E.P. Rodríguez, X. Gao, and L.G. Ferreira. 2002. Overview of the radiometric and biophysical performance of the MODIS vegetation indices. Remote Sensing of Environment 83:195-213.

Karlsen, S.R., A. Tolvanen, E. Kubin, J. Poikolainen, K.A. Høgda, F.E. Wielgolaski, et al. 2008. MODIS-NDVI-based mapping of the length of the growing season in northern Fennoscandia. International Journal of Applied Earth Observation and Geoinformation 10:253-266.

Kramer, K., I. Leinonen, and D. Loustau. 2000. The importance of phenology for the evaluation of impact of climate change on growth of boreal, temperate and Mediterranean forests ecosystems: an overview. International Journal of Biometeorology 44:67-75. 
Laurance, W.F., and G.B. Williamson. 2001. Positive feedbacks among forest fragmentation, drought, and climate change in the Amazon. Conservation Biology 15:1529-1535.

Luo, M., and J.M. Piwowar. 2006. Spatial and temporal responses of NDVI to climate and soil factors in the grassland-forest transition zone of Saskatchewan, Canada. p. 2701-2704. In Geoscience and Remote Sensing Symposium, 2006. IGARSS 2006. Institute of Electrical and Electronics Engineers (IEEE) International Conference, New York, USA.

Maraun, D., and J. Kurths. 2004. Cross wavelet analysis: significance testing and pitfalls. Nonlinear Processes in Geophysics 11:505-514.

Maraun, D., J. Kurths, and M. Holschneider. 2007. Nonstationary Gaussian processes in wavelet domain: Synthesis, estimation and significance testing. Physical Review E75:016707.

Maselli, F. 2004. Monitoring forest conditions in a protected Mediterranean coastal area by the analysis of multiyear NDVI data. Remote Sensing of Environment 89:423-433. doi:10.1016/j. rse.2003.10.020.

Mattar, C., J.A. Sobrino, Y. Julien, B. Franch, y R. Oltra. 2008. Método simple para la identificación de zonas homogéneas de NDVI y temperatura de superficie en la Península Ibérica. Revista de Teledetección 30:92-101.

MODIS. 2012. National Aeronautics and Space Administration NASA, Washington D.C. USA. Available at http://modis.gsfc. nasa.gov/ (accessed August 2012).

Novoa, R., y S. Villaseca. 1989. Mapa Agroclimático de Chile. 60 p. Instituto de Investigaciones Agropecuarias INIA, Ministerio de Agricultura, Santiago, Chile.

ODEPA. 2000. Clasificación de las explotaciones agrícolas del VI Censo Nacional Agropecuario según el tipo de productor y localización geográfica. Documento de Trabajo $N^{\circ} 5.91$ p. Oficina de Estudios y Políticas Agrarias (ODEPA), Santiago, Chile.
Parra, J., J. Sobrino, L. Morales, G. Castellaro, J. Uribe, y N. Gaete. 2006. Aplicación de un algoritmo de Split_Window para la estimación de la temperatura de la superficie terrestre desde datos AVHRR-NOAA. Agricultura Técnica 66:385-392.

Piao, S., J. Fang, L. Zhou, Q. Guo, M. Henderson, W. Ji, et al. 2003. Interannual variations of monthly and seasonal normalized difference vegetation index (NDVI) in China from 1982 to 1999. Journal of Geophysical Research 108:4401-4413. doi:10.1029/2002JD002848.

Primack, D., C. Imbres, R.B. Primack, A.J. Miller-Rushing, and P. Del Tredici. 2004. Herbarium specimens demonstrate earlier flowering times in response to warming in Boston. American Journal of Botany 91:1260-1264.

Rivera, D., M. Lillo, y J.L. Arumí. 2007. Influencia del ENSO en modelos de evaporación: una aproximación usando wavelets. Laboratorio de Hidrología Ambiental, Universidad de Concepción, Concepción, Chile.

Schaefli, B., and H. Gupta. 2007. Do Nash values have value? Hydrological Processes 21:2075-2080.

Wan, Z. 2006. MODIS land surface temperature product user's guide. Institute of Computational Earth System Science, University California, Santa Barbara, California, USA.

Wan, Z., Y. Zhang, Q. Zhang, and Z.-L. Li. 2002. Validation of the land surface temperature products retrieved from Terra Moderate Resolution Imaging Spectroradiometer data. Remote Sensing of Environment 83:163-180.

Wan, Z., Y. Zhang, Q. Zhang, and Z.-L. Li. 2004. Quality assessment and validation of the MODIS global land-surface temperature. International Journal of Remote Sensing 25:261-274.

Yao, J., X. He, X. Li, W. Chen, and D.L. Tao. 2011. Monitoring responses of forest to climate variations by MODIS NDVI: a case study of Hun River upstream, northeastern China. European Journal of Forest Research 131:705-716. doi:10.1007/s10342011-0543-z. 